\title{
Disparities in Outcomes Among Patients Diagnosed With Cancer in Proximity to an Emergency Department Visit
}

Nicholas Pettit

Indiana University

Elisa Sarmiento

Indiana University

Jeffrey Kline ( $\boldsymbol{\sim}$ jkline@wayne.edu )

Wayne State University

\section{Research Article}

Keywords: cancer, disparities, emergency department, lung cancer, health inequities, outcomes, malignancy

Posted Date: January 10th, 2022

DOI: https://doi.org/10.21203/rs.3.rs-1196542/v1

License: (c) (i) This work is licensed under a Creative Commons Attribution 4.0 International License. Read Full License 


\section{Abstract}

A suspected diagnosis of cancer in the emergency department (ED) may be associated with poor outcomes, related to health disparities, however data are limited. This study is a case-control analysis of the Indiana State Department of Health Cancer Registry, and the Indiana Network for Patient Care. First time cancer diagnoses appearing in the registry between January 2013 and December 2017 were included. Cases were patients who had an ED visit in the 6 months before their cancer diagnosis; controls had no recent ED visits. The primary outcome was mortality, comparing ED-associated mortality to nonED-associated. 134,761 first-time cancer patients were identified, including 15,432 (11.5\%) cases. The mean age was same at 65 , more of the cases were Black than the controls $(12.4 \%$ vs $7.4 \%, P<.0001)$ and more were low income (36.4\%. vs $29.3 \%)$. The top 3 ED-associated cancer diagnoses were lung $(18.4 \%)$, breast (8.9\%), and colorectal cancers (8.9\%), whereas the controls were breast (17\%), lung (14.9\%), and prostate cancers $(10.1 \%)$. Cases observed an over three-fold higher mortality, with cumulative death rate of $32.9 \%$ for cases vs $9.0 \%$ for controls $(P<.0001)$. Regression analysis predicting mortality, controlling for many confounders produced an odds ratio of 4.12 (95\% $\mathrm{Cl} 3.72-4.56$ for cases). This study found that an ED visit within 6 months prior to the first time of ICD-coded cancer is associated with Black race, low income and an overall three-fold increased adjusted risk of death. The mortality rates for ED-associated cancers are uniformly worse for all cancer types. These data suggest that additional work is needed to reduce disparities among ED-associated cancer diagnoses.

\section{Introduction}

Cancer is a leading cause of death worldwide. ${ }^{1}$ The number of cancer survivors continues to grow in the face of improving therapies and earlier detection, as well as declining age-standardized incidence rates in men and stable in women. ${ }^{2}$ Improved detection modalities is one reason for these improvements. Longitudinal outcome studies have suggested that each week added to the time to initial cancer treatment is associated with a 1-3\% absolute increased risk of mortality with breast, lung, renal, and pancreatic cancers. ${ }^{3}$ National guidelines exist for cancer screening that are relevant to emergency care. For example, the U.S. Preventive Task Force recommends yearly lung cancer screening with low-dose CT for chronic, heavy smokers, between the ages of 50-80 years old. However, only a minority of patients are appropriately screened as outpatients ( $4 \%$ in the setting of lung cancer), which may contribute to the burden of emergently presenting cancer. ${ }^{4}$ Thus, there is an unmet need to define the burden of emergency department associated cancer diagnoses as to create future interventions, such as ED SBIRTs (screening, brief intervention, referral to treatment) as to either modify the risk factors for cancer (tobacco use) or referral for cancer screening. ${ }^{5}$

Although poorly quantified, preliminary data suggest that many patients are diagnosed with cancer during an ED visit. ${ }^{6}$ Because patients who have cancer diagnosed during ED presentations may have multiple inequities in care (lack of insurance, no primary care, and possibly higher smoking rates), their 
outcomes may be worse. However, since the literature is sparse, and mostly retrospective, little is absolutely known about the outcomes of patients with emergently diagnosed cancer.

In this work, we use data linkage and case-control methodology to characterize the demographics, phenotypes, and outcomes of patients that have emergency department-associated cancer diagnoses. We used a statewide database to examine the rate of recent visit--defined arbitrarily as within six monthsto an ED in patients with newly diagnosed cancer with the inference that the recent visit was the touchpoint where the initial clinical information suggested a possible new cancer diagnosis. We hypothesized that ED-associated cancer diagnoses will suffer higher mortality as compared to non-EDassociated cancer diagnoses.

\section{Methods}

\section{Patients}

This was a retrospective study using data from the Indiana State Department of Health (ISDH) Cancer Registry, the Indiana Network for Patient Care (INPC), supplemented with data from the electronic health records (EHR) of two major hospitals in the greater Indianapolis area.

Patients with their first cancer diagnosis between January 2013 and December 2017 were identified using the ISDH Cancer Registry. To determine presence or absence of a recent ED visit, clinical features and outcomes, patients in the ISDH Cancer registry were co-identified in the INPC research database, which represents one of the largest health information exchanges in the country. Cases were defined as patients with ED visits in the 6 months before their cancer diagnosis were and controls were all others.

The index date for all patients was set as the date of initial cancer diagnosis according to the first posted cancer-defining ICD code. The ICD Oncology Topography codes, the cancer primary site, as well as patient zip code and insurance used at the time of diagnosis were extracted from the ISDH Cancer Registry.

Using unique identifiers for data linkage, demographics and clinical data, comorbid ICD codes were downloaded from the INPC and supplemented with cancer registry data. The Charlson Comorbidity Index (CCl) at time of index was calculated using diagnoses within the year prior to index. Social history (tobacco use, drug use, and alcohol use) was also identified using ICD codes. Tobacco use was supplemented with data available from local hospital electronic health records. Vital status and patient mortality was extracted using Social Security Administration (SSA) death data linked to the INPC. Where SSA data was missing, death data was extracted from the INPC and the ISDH Cancer Registry.

\section{Ethics approval}

This work was approved under exempt status by the Indiana University Institutional Review Board (IRB \#1808879348). De-identified data was used for this study, and informed consent to participate was waived by the IRB. All methods were carried out in accordance with relevant guidelines and regulations.

\section{Statistics}


Patient demographics and characteristics were compared between those patients who did not have an ED visit within six months prior to cancer diagnosis (controls) and those patients who did (cases). To test for differences between groups, the Chi-square test or $95 \%$ confidence interval for differences in proportions were used for bivariate variables, and the Wilcoxon test for continuous variables. Adjusted odds ratios from logistic regression containing the following dependent variables (age, gender, race, SES, drug use, alcohol use, tobacco use, and the Charlson comorbidity index)was used to determine the association of ED diagnosis (cases) with minority status, low SES status and death compared with nonED diagnosis (controls). A generalized estimating equation using the GENMOD procedure was used to adjust for clustering at the city level via zip code which was the estimate of SES. We performed statistical analyses using SAS version 9.4 (SAS Institute, Cary, NC).

\section{Results}

\section{Comparing the two populations}

Table 1 gives the demographics and characteristics of the patients involved in this study, separating patients into controls, those with no-associated ED visits in prior 6 months and compares those to case patients with an associated ED visit within 6 months from the time of cancer diagnosis. In total, 134,761 patients were identified to be diagnosed with cancer within the Indiana Cancer Registry, with 15,432 (11.5\%) cases. First time cancer diagnoses were identified during the 2013-2017 study period, but mortality was included up to 2019. 
Table 1

Characteristics of the study population

\begin{tabular}{|c|c|c|c|}
\hline & $\begin{array}{l}\text { Total } \\
\mathrm{N}=134,761 \\
\mathrm{~N} \\
\text { (percent) }\end{array}$ & $\begin{array}{l}\text { Controls (No ED visit within } \\
\text { six months prior) } \\
\mathrm{N}=119,329 \\
\mathrm{~N} \text { (row percent, column } \\
\text { percent) }\end{array}$ & $\begin{array}{l}\text { Cases (ED visit within six } \\
\text { months prior) } \\
\mathrm{N}=15,432 \\
\mathrm{~N} \text { (row percent, column } \\
\text { percent) }\end{array}$ \\
\hline \multicolumn{4}{|l|}{ Gender } \\
\hline Female & $\begin{array}{l}70,590 \\
(52.4)\end{array}$ & $62,614(46.5,52.5)$ & $7,976(5.9,51.7)$ \\
\hline Male & $\begin{array}{l}64,165 \\
(47.6)\end{array}$ & $56,709(42.1,47.5)$ & $7,456(5.5,48.3)$ \\
\hline Unknown & $6(0.0)$ & $6(0.0,0.0)$ & $0(0.0,0.0)$ \\
\hline \multicolumn{4}{|l|}{ Race } \\
\hline $\begin{array}{l}\text { American Indian or Alaska } \\
\text { Native }\end{array}$ & $89(0.1)$ & $74(0.1,0.1)$ & $15(0.0,0.1)$ \\
\hline Asian & $953(0.7)$ & $874(0.7,0.7)$ & $79(0.1,0.5)$ \\
\hline Black & $\begin{array}{l}10,770 \\
(7.9)\end{array}$ & $8,858(6.6,7.4)$ & $1,912(1.4,12.4)$ \\
\hline $\begin{array}{l}\text { Native Hawaiian or Other } \\
\text { Pacific Islander }\end{array}$ & $31(0.0)$ & $28(0.0,0.0)$ & $3(0.0,0.0)$ \\
\hline Other & $79(0.1)$ & $77(0.1,0.1)$ & $2(0.0,0.0)$ \\
\hline Unknown & $1,185(0.9)$ & $1,098(0.8,0.9)$ & $87(0.1,0.6)$ \\
\hline White & $\begin{array}{l}121,654 \\
(90.2)\end{array}$ & $108,320(80.4,90.8)$ & $13,334(9.9,86.4)$ \\
\hline \multicolumn{4}{|l|}{ Drug Use } \\
\hline No & $\begin{array}{l}133,242 \\
(98.9)\end{array}$ & $118,324(87.8,99.2)$ & $14,918(11.1,96.7)$ \\
\hline Yes & $1,519(1.1)$ & $1,005(0.8,0.8)$ & $514(0.4,3.3)$ \\
\hline \multicolumn{4}{|l|}{ Alcohol Use } \\
\hline No & $\begin{array}{l}131,046 \\
(97.24)\end{array}$ & $116,579(86.51,97.70)$ & $14,467(10.7,93.8)$ \\
\hline Yes & $\begin{array}{l}3,715 \\
(2.76)\end{array}$ & $2,750(2.04,2.30)$ & $965(0.7,6.3)$ \\
\hline Tobacco Use & & & \\
\hline
\end{tabular}




\begin{tabular}{|c|c|c|c|}
\hline & $\begin{array}{l}\text { Total } \\
\mathrm{N}=134,761 \\
\mathrm{~N} \\
\text { (percent) }\end{array}$ & $\begin{array}{l}\text { Controls (No ED visit within } \\
\text { six months prior) } \\
\mathrm{N}=119,329 \\
\mathrm{~N} \text { (row percent, column } \\
\text { percent) }\end{array}$ & $\begin{array}{l}\text { Cases (ED visit within six } \\
\text { months prior) } \\
\mathrm{N}=15,432 \\
\mathrm{~N} \text { (row percent, column } \\
\text { percent) }\end{array}$ \\
\hline No & $\begin{array}{l}98,521 \\
(73.1)\end{array}$ & $89,309(66.3,74.8)$ & $9,212(6.84,59.69)$ \\
\hline Yes & $\begin{array}{l}36,240 \\
(26.9)\end{array}$ & $30,020(22.2,25.2)$ & $6,220(4.62,40.31)$ \\
\hline \multicolumn{4}{|l|}{ Vital Status } \\
\hline Alive & $\begin{array}{l}118,910 \\
(88.2)\end{array}$ & $108,548(80.6,90.9)$ & 10,362 (7.7, 67.2) \\
\hline Deceased & $\begin{array}{l}15,851 \\
(11.8)\end{array}$ & $10,781(8.0,9.0)$ & $5,070(11.8,32.9)$ \\
\hline $\begin{array}{l}\text { Age at Diagnosis, } \\
\text { Median (IQR) }\end{array}$ & $\begin{array}{l}65.0(55.0- \\
74.0)\end{array}$ & $65.0(56.0-73.0)$ & $65.0(54.0-75.0)$ \\
\hline CCl, Median (IQR, Range) & $\begin{array}{l}2.0(1.0- \\
3.0)\end{array}$ & $2.0(1.0-3.0,1.0-19.0)$ & $2.0(1.0-4.0,1.0-17.0)$ \\
\hline
\end{tabular}

Pertinent differences included the finding that African Americans comprised a significantly greater proportion of cases $(12.4 \%$ versus $7.4,95 \% \mathrm{Cl}$ for difference of $5.0 \%=2.3$ to $6.4 \%)$. Furthermore, cases had higher rates of drug, alcohol, and tobacco use than controls at $3.3 \%$ vs $0.8 \%(95 \% \mathrm{Cl}$ for $2.5 \%=0.20$ 0.25 ) for drug use, $6.3 \%$ vs $2.3 \%$ for alcohol use $(95 \% \mathrm{Cl}$ for $4.0 \%=0.14-0.16)$, and $40.3 \%$ vs $25.2 \%$ for tobacco use $(95 \% \mathrm{Cl}$ for $15.1 \%=0.07-0.08)$. In terms of primary outcome, cases had a significantly higher mortality rate of $32.8 \%$ versus $9.0 \%$ ( $95 \% \mathrm{Cl}$ for $23.8 \%=0.23-0.24)$ within a median 116 days for cases and 268 days for controls.

\section{Top cancers per cohort}

Table 2 lists the top 10 malignancies for both cohorts in order of decreasing frequency. The values within each column for frequencies gives two percentages, with the first percentage the overall percentage and the second being the percentage just within controls or cases. For controls, the top 3 cancers in decreasing frequency are breast (18.1\%), lung (14.4\%), and prostate $(10.1 \%)$. Comparatively the most frequently ED-associated cancers were lung (18.4\%), breast (8.9\%), and colon/rectal (8.9\%). 
Table 2

Frequency of cancers among controls and cases.

\begin{tabular}{|c|c|c|c|c|}
\hline \multirow[t]{3}{*}{ Cancer Type* } & $\begin{array}{l}\text { Total } \\
\mathrm{N}=134,761\end{array}$ & $\begin{array}{l}\text { Controls (No ED visit } \\
\text { within six months } \\
\text { prior) } N=119,329\end{array}$ & Cancer Type* & $\begin{array}{l}\text { Cases (ED visit } \\
\text { within six } \\
\text { months prior) }\end{array}$ \\
\hline & \multirow{2}{*}{$\begin{array}{l}\mathrm{N} \\
\text { (percent) }\end{array}$} & \multirow{2}{*}{$\begin{array}{l}N \text { (total cohort } \\
\text { percent, column } \\
\text { percent) }\end{array}$} & & $N=15,432$ \\
\hline & & & & $\begin{array}{l}\mathrm{N} \text { (total cohort } \\
\text { percent, } \\
\text { column } \\
\text { percent) }\end{array}$ \\
\hline Breast & $\begin{array}{l}22,978 \\
(17.05)\end{array}$ & $21,606(16.03,18.11)$ & Bronchus/Lung & $\begin{array}{l}2,838(2.11, \\
18.39)\end{array}$ \\
\hline Bronchus/Lung & $\begin{array}{l}20,023 \\
(14.86)\end{array}$ & $17,185(12.75,14.40)$ & Breast & $\begin{array}{l}1,372(1.02 \\
8.89)\end{array}$ \\
\hline Prostate Gland & $\begin{array}{l}13,593 \\
(10.09)\end{array}$ & $12,677(9.41,10.62)$ & Colon/Rectum & $\begin{array}{l}1,369(1.0 \\
8.87)\end{array}$ \\
\hline Colon/Rectum & $\begin{array}{l}11,887 \\
(8.82)\end{array}$ & $10,518(7.80,8.81)$ & $\begin{array}{l}\text { Hematopoietic and } \\
\text { Reticuloendothelial } \\
\text { Systems }\end{array}$ & $\begin{array}{l}1,066(0.79, \\
6.91)\end{array}$ \\
\hline $\begin{array}{l}\text { Hematopoietic and } \\
\text { Reticuloendothelial } \\
\text { Systems }\end{array}$ & $\begin{array}{l}7,360 \\
(5.46)\end{array}$ & $6,294(4.67,5.27)$ & Prostate Gland & $\begin{array}{l}916(0.68, \\
5.94)\end{array}$ \\
\hline Bladder & $\begin{array}{l}5,887 \\
(4.37)\end{array}$ & $5,068(3.76,4.25)$ & Bladder & $\begin{array}{l}819(0.61 \\
5.31)\end{array}$ \\
\hline Kidney & $\begin{array}{l}5,015 \\
(3.72)\end{array}$ & $4,211(3.12,3.53)$ & Kidney & $\begin{array}{l}804(0.60 \\
5.21)\end{array}$ \\
\hline Corpus Uteri & $\begin{array}{l}4,668 \\
(3.46)\end{array}$ & $4,197(3.11,3.52)$ & Pancreas & $\begin{array}{l}664(0.48 \\
4.17)\end{array}$ \\
\hline Lymph Nodes & $\begin{array}{l}4,264 \\
(3.16)\end{array}$ & $3,662(2.72,3.07)$ & Lymph Nodes & $\begin{array}{l}602(0.45 \\
3.90)\end{array}$ \\
\hline Pancreas & $\begin{array}{l}3,914 \\
(2.90)\end{array}$ & $3,270(2.43,2.74)$ & $\begin{array}{l}\text { Liver And } \\
\text { Intrahepatic Bile } \\
\text { Ducts }\end{array}$ & $475(0.35,3.1)$ \\
\hline
\end{tabular}

\section{Comparing Mortality Between Cancers}

Figure 1 (S1 Table) compares the cumulative mortality rates for 9 cancer diagnoses during the 5-year study period, (since the 10th cancer in each was different between the two). The percentage of mortality for all nine cancer types were consistently higher in cases compared with controls. A concerning $45 \%$ relative difference exists between cases and controls for pancreatic cancer. Figure 2 shows Kaplan Meier 
survival curves for these nine cancers and demonstrates a consistently worse survival for cases versus controls up until 5 years of follow-up ( $\mathrm{P}<0.001$ log-rank statistic).

\section{Socioeconomic Status and Racial Outcomes}

Table 3 compares SES data between cases and controls, and was assigned by zip code into 5 different categories, namely below/near poverty, low income, middle class, upper middle class, and highest tax bracket. ${ }^{7,8}$ Among cases, $36.9 \%$ were low income or below poverty level, compared with $29.5 \%$ in the controls $(95 \% \mathrm{Cl}$ for difference of $7.4 \%=0.03-0.04)$. Supplemental table 3 breaks down the mortality among cases and controls based upon SES. Similar to the data presented in Figures 1 and 2, mortality among cases consistently worse; overall, $36.3 \%$ of low-income cases having died in the study period, whereas only $11 \%$ low-income controls died.

Table 3

Socioeconomic status for controls vs. cases.

\begin{tabular}{|c|c|c|}
\hline \multirow{3}{*}{$\begin{array}{l}\text { Total } \\
\mathrm{N}=134,761\end{array}$} & $\begin{array}{l}\text { Controls (No ED visit within six } \\
\text { months prior) }\end{array}$ & $\begin{array}{l}\text { Cases (ED visit within six months } \\
\text { prior) }\end{array}$ \\
\hline & $N=118,599$ & $N=15,344$ \\
\hline & $\begin{array}{l}\mathrm{N} \text { (total cohort percent, column } \\
\text { percent) }\end{array}$ & $\begin{array}{l}\mathrm{N} \text { (total cohort percent, column } \\
\text { percent) }\end{array}$ \\
\hline \multicolumn{3}{|l|}{$\begin{array}{l}\text { Socioeconomic } \\
\text { status* }\end{array}$} \\
\hline $\begin{array}{l}\text { Below or near poverty } \\
\text { level }\end{array}$ & $214(0.16,0.18)$ & $31(0.02,0.20)$ \\
\hline Low income & $34,794(25.98,29.34)$ & $5,583(4.17,36.39)$ \\
\hline Middle class & $83,568(62.39,70.46)$ & $9,729(7.26,63.41)$ \\
\hline Upper middle class & $10(0.01,0.01)$ & $0(0,0)$ \\
\hline Highest tax brackets & $13(0.01,0.01)$ & $1(0,0.01)$ \\
\hline
\end{tabular}

Black race consistently worsened cancer prognosis among cases (S2 Table). For breast cancer, mortality rate was $12.1 \%$ for Black patients who were ED cases, versus a mortality rate of $5.5 \%$ for Black patients who were in the control group $(95 \% \mathrm{Cl}$ for $6.6 \%$ difference $=0.01-0.04)$. Black patients comprised $18.2 \%$ of the breast cancer patients among cases versus $8.0 \%$ of controls $(95 \% \mathrm{Cl}$ for $10.1 \%$ difference $=0.06$ 0.09). These trends continued for lung cancer, with a mortality rate of $58.7 \%$ among Black patients in case group, compared with a mortality rate of $22.4 \%$ among the control group. 


\section{Controlling for confounders}

Table 4 shows the result of logistic regression to examine the effect of case or control status on mortality while controlling for confounding variables. The equation was designed to control for clustering by city (via zip code) and also for seven other potential independent predictor variables (age, gender, race, SES, drug use, alcohol use, tobacco use, and the $\mathrm{CCl}$ ) and found cases had an increased risk of death over controls with an adjusted odds ratio of $4.12(95 \% \mathrm{Cl} 3.72-4.56)$. After these corrections, the lower limit of the $95 \% \mathrm{Cl}$ for mortality consistently remained above 1.0 for case versus control status for all cancer.

Table 4

Mortality risk based upon recent emergency department (ED) visit, minority and socioeconomic status

\begin{tabular}{|ll|}
\hline Recent ED visit & Odds Ratio $(95 \% \mathrm{Cl}){ }^{*}$ \\
\hline Seen 6 months prior (Unadjusted) & $4.93(4.40-5.51)$ \\
\hline Seen 6 months prior (Adjusted**) & $4.12(3.72-4.56)$ \\
\hline Minority status (non-whites) & Odds Ratio $(95 \% \mathrm{Cl}){ }^{\star}$ \\
\hline Seen 6 months prior (Unadjusted) & $1.55(1.24-1.94)$ \\
\hline Seen 6 months prior (Adjusted**) & $0.97(0.96-0.99)$ \\
\hline Low socioeconomic status & Odds Ratio $(95 \% \mathrm{Cl}){ }^{\star}$ \\
\hline Seen 6 months prior (Unadjusted) & $1.37(1.01-1.87)$ \\
\hline Seen 6 months prior (Adjusted**) & $1.19(0.94-1.50)$ \\
\hline$*$ Odds of death comparing cases with controls. & \\
$* \star$ Adjusted for age, gender, race, SES, drug use, alcohol use, tobacco use, \& Charlson Score. \\
\hline
\end{tabular}

\section{Discussion}

Our findings show uniformly worsened outcomes of all patients during a period of five years, especially in minority and low-income patients, diagnosed with new cancer diagnosed in temporal proximity to an ED visit. These data infer that patients with undiagnosed cancer who rely on the ED as a source of primary medical care will have a worsened outcome compared with patients who have organized medical care. ${ }^{6}$ Prior work from the United Kingdom's "Routes-to-Diagnosis" conducted by the Public Health England, suggested $23 \%$ of newly diagnosed cancer patients presented emergently and survival rates were much lower for those emergent presenters, which is similar to what we discovered in this work. ${ }^{9}$

In the US, a study from Michigan, lung and colorectal cancer patients with ED-associated cancer diagnosis had more advanced staged cancer and were more likely to be Black than those diagnosed without a recent ED visit, but no data on mortality were presented. ${ }^{10}$ In this study, the authors chose a 
conservative approach by defining an ED-diagnosed cancer as one that had an ED visit in the month of or month before the diagnosis of cancer, however, prior to this publication there is no precedent for defining an ED-associated cancer. Instead, we chose 6 months as our conservative time point as to define EDassociated cancer, as there is substantial evidence that ambulatory follow-up compliance after ED discharge is poor, and has been estimated to be between $26 \%$ and $56 \%$ depending on the ED population. ${ }^{11}$ Additionally, there is some evidence that suggests almost one third of patients with new onset cancer experience delays of over 90 days, and thus there is no precedent for establishing the optimal time from ED visit to cancer diagnosis. ${ }^{12}$ Among 9,470,626 ED visits among Medicare beneficiaries aged 65 and older, nearly $30 \%$ lacked ambulatory follow-up at 30 days, with lower rates of ambulatory follow-up observed among those of Black race and seen in rural EDs. ${ }^{13}$ Further, a study from Western Australia demonstrated that of 1358 people with incident breast, prostate, colorectal, and lung cancers the diagnostic interval from symptom to diagnosis ranged from 92-108 days, further suggesting the time to cancer diagnosis can exceed several months. ${ }^{14}$ Rural health disparities exacerbate the time to cancer treatment and ultimately mortality, due to long travel times, low availability of clinical trials, and additional health burdens, an issue that is well observed in the state of Indiana. ${ }^{15}$ Thus, additional research is clearly needed among US populations to delineate and improve the time to cancer diagnosis and treatment for ED-suspected cancer patients.

It has been demonstrated that emergent presentations of cancer are associated with lower curative rates and treatments, even when compared to cancers diagnosed "electively" (even at the same stage). ${ }^{16}$ The present data in Figure 2, together with prior findings support the inference that patients who have a diagnosis of cancer temporally connected with an ED visit, suffer from a disparity in their odds of survival. From a health services standpoint, potentially modifiable causes for this disparity include lack of access to primary medical care and cancer screening before diagnosis, increased rate of tobacco and alcohol use, worsened uncontrolled comorbidities at the time of diagnosis, and lack of access to specialty cancer care after diagnosis. Thus, additional work should focus on reducing the time to cancer diagnosis as expedited diagnosis of symptomatic cancer likely benefits patients' survival and improved quality of life as demonstrated in a systematic review of over 200 studies. $^{17}$

This work employed a state-wide assessment of cancer diagnoses in the state of Indiana. From this, numerous patient factors appear to contribute to the observed mortality and worse outcomes, namely race and socioeconomic status. Meanwhile, factors such as age and sex appear to have little relationship between the association of diagnosis and mortality. This is compared to other works where older age ( $\geq 85$ years old) are 2.5 times more likely to present with an emergent diagnosis of cancer, when compared to a 65-74-year-old cohort. ${ }^{18}$ Those authors conclude that cancer and age are likely to reflect disease specific factors. Further, our work we excluded pediatric patients ( $<18$ years old), and it is well known that more than half of patients that present with de novo cancer diagnoses in the ED are emergently diagnosed. ${ }^{19}$ 
What limited evidence exists from data obtained in the United States, has demonstrated associations between socioeconomic status and the diagnosis of cancer as an emergency. African Americans in one study had increased odds of emergently diagnosed colorectal cancer (AOR 1.5, 95\% Cl 1.38-1.63) as compared to a similar white cohort. ${ }^{20}$ This disparity not only exists among the diagnosis of cancer but in the primary and secondary preventions among lower SES populations. Colorectal screening, despite its efficacy and recommendations, has been shown to be low among African Americans and those with low SES, demonstrating an opportunity or intervening on this high risk population in the ED. ${ }^{21}$ Furthermore, the low SES population have inequities that result in poor lifestyle choices, some of which (smoking status, diet, physical activity) are preventable and modifiable if this population had access to equitable opportunities. Cancer mortality among this population has an association between mortality and modifiable risk factors, again at current date are not routinely performed in the ED. ${ }^{22}$ Blacks are diagnosed with breast and lung cancer in the cases versus controls and their outcomes appear to be worse. We speculate that blacks are more dependent upon EDs than whites for unscheduled, emergent care, and thus are more likely to present to an ED emergently for their undiagnosed malignancy. ${ }^{23}$ Similar phenomenon can be applied to whites with low SES, where patients of low SES are more reliant on the ED for their care and are more likely to present emergently with their undiagnosed cancer. ${ }^{24,25}$ These data suggest race and socioeconomic status are more important than other factors, such as comorbidities, since the $\mathrm{CCl}$ was equal. While not examined in this large data analyses, there is growing evidence that African Americans have more aggressive tumor biology, such as in several breast cancer studies, which can be speculated that this also contributes to these patients presenting more emergently for their undiagnosed cancer. ${ }^{26}$

Of the cancers that have proven screenings that demonstrate success, lung and colorectal cancers do markedly worse when associated with an ED-visit, $54 \%$ vs $18 \%$ mortality for lung cancer $(P<.0001)$, and $26.4 \%$ vs $9 \%$ for colorectal cancer $(P<.0001)$. Breast cancer also has a successful screening modality, namely mammography, and suffers from similar poor outcomes when associated with an ED visit, $11.9 \%$ mortality vs $3.4 \%$, ED to non-ED associated. ${ }^{27}$ Prostate cancer screening is controversial and recommendations vary by organization and country, regardless, a screening modality is available and those diagnosed with prostate cancer associated with an ED visit have higher mortality than those that don't (13.2\% vs 3.5\%). ${ }^{28}$ Lastly, cervical cancer also is frequently screened for as outpatients and $22 \%$ of those seen in the ED were dead, versus $7.4 \%$ of those not seen in the ED. This evidence is supported by known disparities in cancer screening, with minority patients experiencing greater delays in evaluation and screening for cancer, leading to suboptimal treatment among those patients subsequently diagnosed with cancer. ${ }^{29}$

Previous research has called for both improving the outcomes of patients that are diagnosed with cancer through an emergent presentation, as well as helping to reduce the burden of emergent diagnoses by improving cancer screening. ${ }^{6,30}$ This is likely a systems issue, but plausible future steps is utilizing the ED space for more than just emergent care. Average length of stays in ED has multiple variables that impact exact time frame which patients sit in the ED, but in one paper an average a patient can expect a wait of 4 
hours. ${ }^{31}$ As the trend of increasing length of stay continues to increase nationwide, EDs are experiencing the unfortunate phenomena of ED crowding which has been well demonstrated to be associated with increased hospital death. ${ }^{32}$ We propose future work in developing interventions for this at risk population while in the ED, similar to what has been performed for rapid hepatitis screening and cervical cancer screening in urban EDs, demonstrating proof of concept and utilizing the ED space for more than emergent care. ${ }^{33,34}$ Similar revolutionary changes in ED workflow for improving the overall health of ED patients has been adopted with universal HIV screening in the ED, as well as universal suicide screening in EDs. ${ }^{35,36}$ Intervening on this population is challenging but supported by a Cochrane Review, guaiac fecal immunochemical test (FIT) can reduce colorectal mortality by $15 \%$, and providing appropriately chosen patients with home use FIT tests through primary care has improved screening rates, sustaining a screening rate of $75 \% .{ }^{37,38}$ Currently screening routinely for cancer does not occur in the emergency setting, but for many vulnerable patients (uninsured, lower SES, racial minorities), the emergency room serves as the only opportunity for routine care and we should begin to explore alternative strategies to maximally improve the care of these patients. ${ }^{39}$ Removing the barriers to cancer screening, such as providing patients with FIT cards prior to discharge may represent an opportunity to increase adherence to CRC screening and reduce the burden of emergently diagnosed CRC. ${ }^{40}$ Novel approaches need be undertaken at the systems and health policy level to address the disparities that are well demonstrated among ED-associated cancer diagnoses.

\section{Limitations}

There are limitations to this study, namely the retrospective methodology to obtaining the administrative data. A diagnosis of cancer, while suspected in the ED, usually occurs weeks to months after the actual ED encounter, and thus confirming linkage from a suspected ED visit and a diagnosis is challenging. Further, patient stage and tumor specific biology are not included on the ICD-coded diagnosis and thus knowing the stage and extent of disease is not available without retrospective chart review. Regardless, we made an inference that being diagnosed with cancer within 6 months of a recorded ED visit, meant those ED physicians had an opportunity to diagnose asymptomatic cancer, if that ED visit wasn't directly related to the presentation of emergent cancer diagnosis. The relationship between the ED visit and the diagnosis of cancer are unclear, due to lack of detailed ED visit information as well as most patients that are discharged from the ED have symptom-based discharge diagnoses as opposed to a definitive discharge diagnosis. ${ }^{41}$ Additionally, no knowledge is known about previous screenings and primary care follow up, thus no inference can be made to know whether or not screening may have reduced the likelihood of the found associations. The lack of follow-up knowledge means we can't examine the relationship between mortality and inadequate access to expert care, but the correction for clustering on logistic analyses suggests this is not just a result of location. Ultimately, it is difficult to determine if the observed outcome differences primarily reflect lead-time bias, health care disparities, or other factors, but comparing to the limited available data primarily from Europe, these data clearly present a concerning trend for patients with a new diagnosis of cancer. 
Further limitations include those cancers that are so advanced that tissue biopsy is not obtained, or patients prefer to not seek treatment. Lastly, pediatric cancers and their association with being emergently diagnosed in the ED were not explored in this study. No pediatric cancers have preventable or modifiable risk factors, and as such the goal of this work is to find interventions on cancers that can be prevented with lifestyle modification (smoking cessation, weight loss), or caught earlier with ageappropriate screening.

\section{Conclusions}

Patients diagnosed with cancer with an associated ED visit within 6 months prior to their ICD-code cancer diagnosis are associated with poor outcomes, specifically increased mortality, as compared to a cohort that did not have an ED visit within 6 months prior to their diagnosis. Lung, breast, and colorectal are the most frequently ED-associated cancer diagnoses, with upwards of $50 \%$ mortality as compared to non-ED associated cancers. Further, there are associated racial and socioeconomic disparities among those diagnosed, both in cancer type and frequency, and mortality. These data are among the first to our knowledge that describe patients in the United States, among a statewide database. They further suggest that ED-associated cancer diagnoses offers an opportunity for additional research to understand the associations between diagnoses and socioeconomic and racial disparities. Given existing literature is limited to retrospective, database analyses, future work should be aimed at prospective studies as to guide future interventions to help reduce the disparities and reduce the mortality among ED-associated cancer diagnoses.

\section{Abbreviations}

emergency department (ED), Charlson Comorbidity Index (CCI)

\section{Declarations}

\section{Author Contributions:}

NP and JK designed and collected the data. ES analyzed the data. NP, ES, and JK wrote the manuscript.

\section{Acknowledgements:}

none

\section{Competing interests:}

The authors declare no competing interests.

\section{Data availability:}


All data generated or analyzed during this study are included in this published article (and its Supplementary information files).

\section{Acknowledgements:}

We would like to thank the research database managers at The Regenstrief Institute for helping cultivate the data for these analyses.

\section{References}

1. Heron, M. \& Anderson, R. N. Changes in the Leading Cause of Death: Recent Patterns in Heart Disease and Cancer Mortality. NCHS Data Brief, 1-8 (2016).

2. Miller, K. D. et al. Cancer treatment and survivorship statistics, 2019. CA Cancer J Clin 69, 363-385, doi:10.3322/caac.21565 (2019).

3. Khorana, A. A. et al. Time to initial cancer treatment in the United States and association with survival over time: An observational study. PLoS One 14, e0213209, doi:10.1371/journal.pone.0213209 (2019).

4. Colson, Y. L., Shepard, J. O. \& Lennes, I. T. New USPSTF Guidelines for Lung Cancer Screening: Better but Not Enough. JAMA Surg, doi:10.1001/jamasurg.2021.0242 (2021).

5. Bernstein, E., Bernstein, J. A., Stein, J. B. \& Saitz, R. SBIRT in emergency care settings: are we ready to take it to scale? Acad Emerg Med 16, 1072-1077, doi:10.1111/j.1553-2712.2009.00549.x (2009).

6. Zhou, Y. et al. Diagnosis of cancer as an emergency: a critical review of current evidence. Nat Rev Clin Oncol 14, 45-56, doi:10.1038/nrclinonc.2016.155 (2017).

7. Bureau, U. S. C. American Community Survey.

8. CUP), H. C. a. U. P. H. NIH Description of Data Elements. (2008).

9. Service, N. C. R. a. A. Routes to Diagnosis - NCIN Data Briefing. (2010).

10. Sikka, V. \& Ornato, J. P. Cancer diagnosis and outcomes in Michigan EDs vs other settings. Am J Emerg Med 30, 283-292, doi:10.1016/j.ajem.2010.11.029 (2012).

11. Kyriacou, D. N., Handel, D., Stein, A. C. \& Nelson, R. R. BRIEF REPORT: Factors affecting outpatient follow-up compliance of emergency department patients. J Gen Intern Med 20, 938-942, doi:10.1111/j.1525-1497.2005.0216_1.x (2005).

12. Vidaver, R. M., Shershneva, M. B., Hetzel, S. J., Holden, T. R. \& Campbell, T. C. Typical Time to Treatment of Patients With Lung Cancer in a Multisite, US-Based Study. J Oncol Pract 12, e643-653, doi:10.1200/JOP.2015.009605 (2016).

13. Lin, M. P., Burke, R. C., Orav, E. J., Friend, T. H. \& Burke, L. G. Ambulatory Follow-up and Outcomes Among Medicare Beneficiaries After Emergency Department Discharge. JAMA Netw Open 3, e2019878, doi:10.1001/jamanetworkopen.2020.19878 (2020).

14. Emery, J. D. et al. The Improving Rural Cancer Outcomes Trial: a cluster-randomised controlled trial of a complex intervention to reduce time to diagnosis in rural cancer patients in Western Australia. $\mathrm{Br} J$ 
Cancer 117, 1459-1469, doi:10.1038/bjc.2017.310 (2017).

15. Levit, L. A. et al. Closing the Rural Cancer Care Gap: Three Institutional Approaches. JCO Oncol Pract 16, 422-430, doi:10.1200/OP.20.00174 (2020).

16. Gunnarsson, H. et al. Heterogeneity of colon cancer patients reported as emergencies. World J Surg 38, 1819-1826, doi:10.1007/s00268-014-2449-7 (2014).

17. Neal, R. D. et al. Is increased time to diagnosis and treatment in symptomatic cancer associated with poorer outcomes? Systematic review. Br J Cancer 112 Suppl 1, S92-107, doi:10.1038/bjc.2015.48 (2015).

18. Abel, G. A., Shelton, J., Johnson, S., Elliss-Brookes, L. \& Lyratzopoulos, G. Cancer-specific variation in emergency presentation by sex, age and deprivation across 27 common and rarer cancers. $\mathrm{Br} J$ Cancer 112 Suppl 1, S129-136, doi:10.1038/bjc.2015.52 (2015).

19. Elliss-Brookes, L. et al. Routes to diagnosis for cancer - determining the patient journey using multiple routine data sets. Br J Cancer 107, 1220-1226, doi:10.1038/bjc.2012.408 (2012).

20. Pruitt, S. L., Davidson, N. O., Gupta, S., Yan, Y. \& Schootman, M. Missed opportunities: racial and neighborhood socioeconomic disparities in emergency colorectal cancer diagnosis and surgery. BMC Cancer 14, 927, doi:10.1186/1471-2407-14-927 (2014).

21. Warren Andersen, S. et al. Association of Race and Socioeconomic Status With Colorectal Cancer Screening, Colorectal Cancer Risk, and Mortality in Southern US Adults. JAMA Netw Open 2, e1917995, doi:10.1001/jamanetworkopen.2019.17995 (2019).

22. Hastert, T. A., Ruterbusch, J. J., Beresford, S. A., Sheppard, L. \& White, E. Contribution of health behaviors to the association between area-level socioeconomic status and cancer mortality. Soc Sci Med 148, 52-58, doi:10.1016/j.socscimed.2015.11.023 (2016).

23. Blanchard, J. C., Haywood, Y. C. \& Scott, C. Racial and ethnic disparities in health: an emergency medicine perspective. Acad Emerg Med 10, 1289-1293, doi:10.1111/j.1553-2712.2003.tb00615.x (2003).

24. Krieg, C., Hudon, C., Chouinard, M. C. \& Dufour, I. Individual predictors of frequent emergency department use: a scoping review. BMC Health Serv Res 16, 594, doi:10.1186/s12913-016-1852-1 (2016).

25. Wachelder, J. J. H. et al. Association of socioeconomic status with outcomes in older adult community-dwelling patients after visiting the emergency department: a retrospective cohort study. BMJ Open 7, e019318, doi:10.1136/bmjopen-2017-019318 (2017).

26. Keenan, T. et al. Comparison of the Genomic Landscape Between Primary Breast Cancer in African American Versus White Women and the Association of Racial Differences With Tumor Recurrence. $J$ Clin Oncol 33, 3621-3627, doi:10.1200/JC0.2015.62.2126 (2015).

27. Caughran, J. et al. The Effect of the 2009 USPSTF breast cancer screening recommendations on breast cancer in Michigan: A longitudinal study. Breast J 24, 730-737, doi:10.1111/tbj.13034 (2018).

28. Kim, E. H. \& Andriole, G. L. Prostate-specific antigen-based screening: controversy and guidelines. BMC Med 13, 61, doi:10.1186/s12916-015-0296-5 (2015). 
29. Fiscella, K. et al. Eliminating disparities in cancer screening and follow-up of abnormal results: what will it take? J Health Care Poor Underserved 22, 83-100, doi:10.1353/hpu.2011.0023 (2011).

30. Goodyear, S. J. et al. The effects of population-based faecal occult blood test screening upon emergency colorectal cancer admissions in Coventry and north Warwickshire. Gut 57, 218-222, doi:10.1136/gut.2007.120253 (2008).

31. Mentzoni, I., Bogstrand, S. T. \& Faiz, K. W. Emergency department crowding and length of stay before and after an increased catchment area. BMC Health Serv Res 19, 506, doi:10.1186/s12913-019-43424 (2019).

32. Boulain, T., Malet, A. \& Maitre, O. Association between long boarding time in the emergency department and hospital mortality: a single-center propensity score-based analysis. Intern Emerg Med, doi:10.1007/s11739-019-02231-z (2019).

33. White, D. A., Anderson, E. S., Pfeil, S. K., Trivedi, T. K. \& Alter, H. J. Results of a Rapid Hepatitis C Virus Screening and Diagnostic Testing Program in an Urban Emergency Department. Ann Emerg Med 67, 119-128, doi:10.1016/j.annemergmed.2015.06.023 (2016).

34. Hogness, C. G., Engelstad, L. P., Linck, L. M. \& Schorr, K. A. Cervical cancer screening in an urban emergency department. Ann Emerg Med 21, 933-939, doi:10.1016/s0196-0644(05)82931-2 (1992).

35. Orkin, C. et al. Incorporating HIV/hepatitis B virus/hepatitis C virus combined testing into routine blood tests in nine UK Emergency Departments: the "Going Viral" campaign. HIV Med 17, 222-230, doi:10.1111/hiv.12364 (2016).

36. Heyland, M., Delaney, K. R. \& Shattell, M. Steps to Achieve Universal Suicide Screening in Emergency Departments: A Call to Action. J Psychosoc Nurs Ment Health Serv 56, 21-26, doi:10.3928/0279369520180503-03 (2018).

37. Bakhai, S., Ahluwalia, G., Nallapeta, N., Mangat, A. \& Reynolds, J. L. Faecal immunochemical testing implementation to increase colorectal cancer screening in primary care. BMJ Open Qual 7, e000400, doi:10.1136/bmjoq-2018-000400 (2018).

38. Nicholson, B. D., Thompson, M., Price, C. P., Heneghan, C. \& Pluddemann, A. Home-use faecal immunochemical testing: primary care diagnostic technology update. Br J Gen Pract 65, 156-158, doi:10.3399/bjgp15X684229 (2015).

39. Begley, C. E., Vojvodic, R. W., Seo, M. \& Burau, K. Emergency room use and access to primary care: evidence from Houston, Texas. J Health Care Poor Underserved 17, 610-624, doi:10.1353/hpu.2006.0098 (2006).

40. Cusumano, V. T. \& May, F. P. Making FIT Count: Maximizing Appropriate Use of the Fecal Immunochemical Test for Colorectal Cancer Screening Programs. J Gen Intern Med 35, 1870-1874, doi:10.1007/s11606-020-05728-y (2020).

41. Slovis, B. H. et al. Identifying Emergency Department Symptom-Based Diagnoses with the Unified Medical Language System. West J Emerg Med 20, 910-917, doi:10.5811/westjem.2019.8.44230 (2019). 


\section{Supplemental Tables}

Supplemental Tables are not available with this version.

\section{Figures}

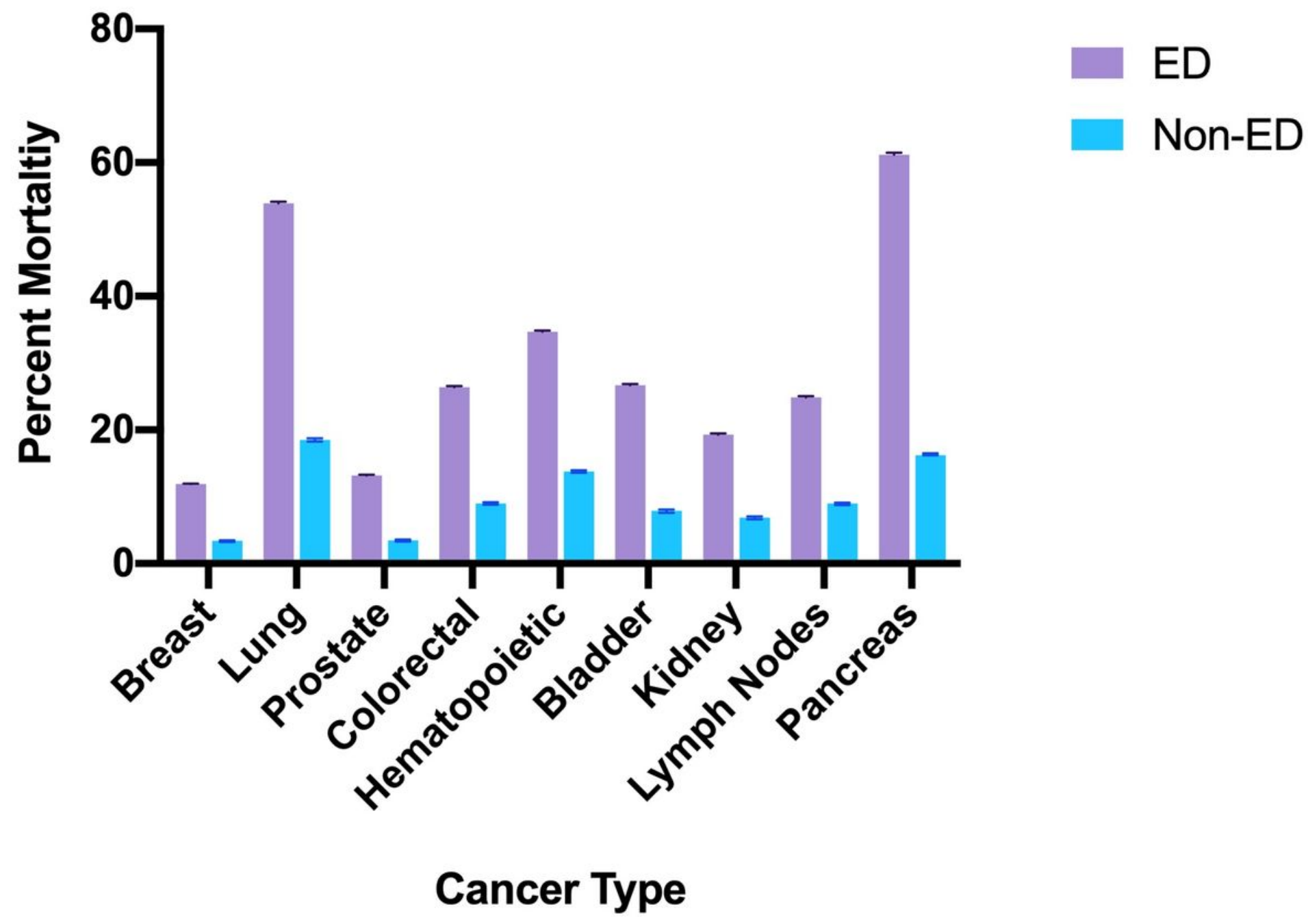

Figure 1

Bar graph comparing mortality among nine cancers. Bar graph comparing mortality percentages from cases compared to controls for the top 9 most common cancers, over 5-year study period, error bars representing $95 \% \mathrm{Cl}$. 


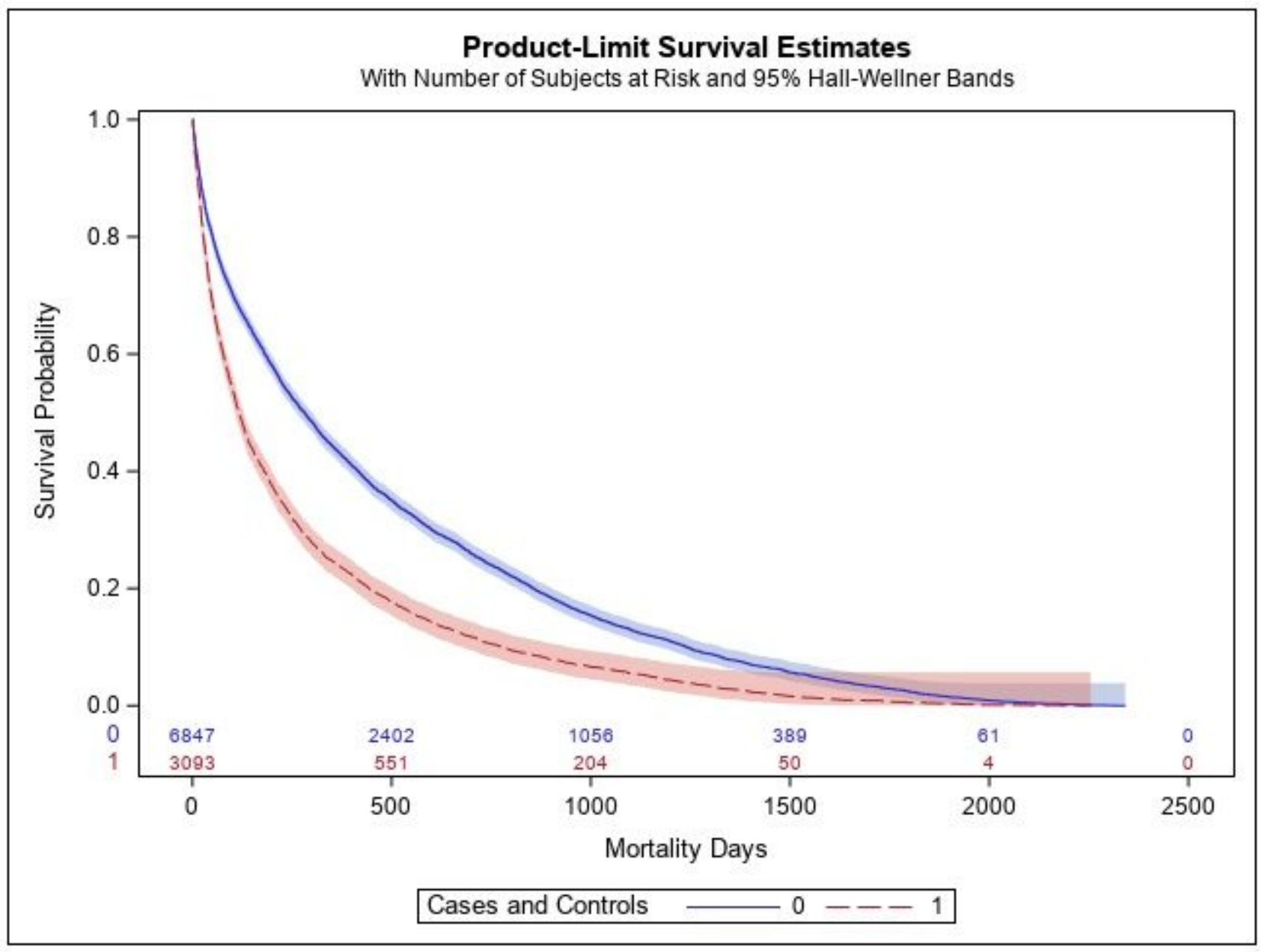

Figure 2

Survival Curve for Cases vs. Controls. Kaplan Meier survival curve comparing days lived from cases (blue line) to controls (red line). 